\title{
Can online pharmacies address health inequalities in low- and middle-income countries? The International Forum on Patient Safety and Safe Access to Online Pharmacies, New Delhi, India (1-2 March 2017) thinks they will
}

\author{
Jolanta Bilińska, Kawaldip Sehmi
}

International Alliance of Patients' Organizations, London, UK

ADDRESS FOR CORRESPONDENCE: Kawaldip Sehmi, International Alliance of Patients' Organizations, 49-51 East Road London, N16AH United Kingdom, e-mail: kawaldip@iapo.org.uk

The Government of India, Alliance for Safe Online Pharmacies (ASOP), Consumer Online Foundation India, and other state and non-state Indian actors hosted a two-day International Forum on Patient Safety and Safe Access to Online Pharmacies at a purpose-built policymaking hub, the India Habitat Centre, in the heart of New Delhi's Lodhi Estate in early March 2017. The event was attended by over 160 health policy elites and three of the most influential global health regulators: the US Food and Drug Administration (FDA), the European Medicines Agency, through the UK Medicines and Healthcare Regulatory Agency, and the World Health Organization's Regional Office for South-East Asia.

Why did these policy leaders and regulators turn up at this event in a lower-middle-income country?

First, the Indian pharmaceutical industry is a waking giant; it is already supplying many of its generic and even innovative medicines to foreign healthcare systems, including the UK's NHS and Medicaid/Medicare/ Obamacare in the US. Secondly, India is a colossus in the field of information technology (IT) and software engineering, especially in telemedicine. Indian companies such as InfoSys, Tata Consultancy, and WIPRO are competitive globally. Put the two above factors together and you get your answer: online pharmacies (OPs) are going to become big business in the future, with India set to dominate the market for software and generic products. OPs, the forum heard, are offering an opportunity for pharmaceutical companies to expand their markets directly to patients, bypassing all middlemen. Like the online air travel business, they promise patients an accessible, 24-7, quality medicines market at affordable prices. There will be no overhead costs, such as heating and lighting, large shop fronts and rentals, nor the security and cleaning services required by brick-and-mortar pharmacies. OPs, thanks to economies of scale and IT use, make medicines more accessible and affordable. They would therefore address health inequalities and improve choice. For patient advocates and regulators present there, the forum provided reassuring messages that in low- and middle-income countries OPs will solve quality and safety issues along the supply chain through traceability and remote intelligent monitoring algorithms. Unethical practices and fraud found in traditional medicines networks will not exist online as ALL transactions along the OP supply chain will be electronically logged and any unusual trading patterns detected. Most importantly, drug batch numbers and accounts will be traceable and any fraud identified and dealt with immediately. Twenty years ago many people dismissed online business and social media as passing fads. Many established businesses were caught out as new IT-savvy entrepreneurs moved in with new operating models. The paradigm-shifting technology disrupted many brickand-mortar establishments in sectors such as travel, insurance, financial services and banking. Today we live online', seeking medical advice from sites like WebMD and complaining about health services on our Facebook pages and Twitter accounts. We even seek matrimonial services online now, though this was once thought to be far too sensitive and personal. The US Minister Counselor for Commercial Affairs in India, Patrick Santillo, 
began the keynote address by saying his government has given its full support to online pharmacies globally and is investing in the end-to-end safeguarding of supply chains. By identifying and regulating domain name providers, server hosts, online transactions, aggregators, shippers, customs and clearing agents, couriers and the landlord/residents at the delivery address, the US and its intelligence agencies could eliminate substandard, spurious, falsely labelled, falsified and counterfeit (SSFFC) medical products along the supply chain. Anyone trafficking SSFFCs gets the same treatment as terror groups. Their transactions are blocked, accounts frozen and assets seized. The credit card companies MasterCard and VISA have unveiled their own strategies. Both have safety nets involving checks and balances at the level of retailers, card issuers, banks, and consumers. They have intelligent systems that rapidly identify 'abnormal patterns' in online transactions and quickly shut down unsafe and fraudulent sites. Online transactions can be traced, in order to 'follow the money' and solve crimes.

\section{PHARMACY}

Domain name providers then stepped up to provide the policy-makers in attendance with a comprehensive solution that could basically make the whole supply chain secure. The National Association of Boards of Pharmacy (NABP) is a professional organization that supports the state boards of pharmacy in protecting public health in the US. It is spearheading the 'Dot Pharmacy' (.pharmacy) initiative and works with regulators of internation- al laws and standards. You can get a .pharmacy domain name (like .gov) only if you satisfy ethical, quality, and pharmacovigilance criteria set forth by the NABP. This has the potential of wiping out all 'cowboys' in the online pharmacy racket. No one will sell or buy certified medicines online other than via a pharmacy domain. One myth global regulators and policy elite debunked at the meeting was that OPs cannot work in low- and middle-income countries (LMICs). Many strategists, mostly coming from high-income countries, say LMICs are not ready for this innovation. Evidence offered at the forum proved the contrary. Today, online services, especially in LMICs, are the norm and not the exception. LMICs are expanding not only consumer services, but also governance and public services online. Online pharmacies in LMICs have the potential to address quality, safety, access, and affordability issues within the essential medicines market for patients, and may result in addressing health inequalities as well.

\section{ACKNOWLEDGEMENTS}

Editors would like to acknowledge the invaluable assistance of Mr. Scott Thompson in the preparation of the final version of this article.

\section{DICLOSURE}

Authors report no conflict of interest.

\section{AUTHORS' CONTRIBUTIONS}

$\mathrm{JB}, \mathrm{KS}$ prepared concept of the publication and finally approved it. JB wrote the article.

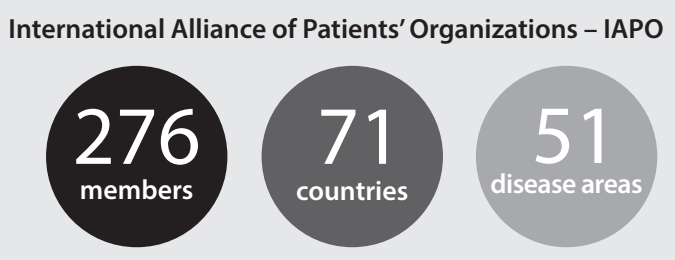

IAPO is a patient-led organization independent of government, industry and other professional organizations. IAPO's strategic direction is set by our members through our Governing Board. We are committed to ensuring that IAPO and our members remain independent, believing that this is the most effective way to represent the needs and views of patients. IAPO strives to be fully representative of patients' needs and views. Given the diversity of IAPO's membership, we recognize the challenges this entails. We ensure that consultation with members is an integral part of our work including undertaking an annual survey of members' needs and using all this information to guide future projects and accurately represent our members at an international level. IAPO strives to have clear processes for its work including its decision-making processes, utilizing its website and other appropriate communication tools. IAPO has an open, transparent framework to guide its funding agreements. IAPO works in partnership with a number of organizations; all formal partnerships are governed by clear and transparent guidelines. Our vision is to see patients at the centre of healthcare throughout the world. Our mission is to help build patient-centred healthcare worldwide.

- We have published a number of world firsts in terms of policies, strategies and initiatives that promote patient-centred healthcare around the world. A key example of this is our Declaration on Patient-Centred Healthcare.

- We have advised on and guided the creation of policy and strategy for organizations such as the World Health Organization.

- We are recognized by, and work with, international organizations such as the World Health Organization, the International Council of Nurses, the International Pharmaceutical Federation, the World Medical Association, and the United Nations Economic and Social Council.

- We are the global voice for over two hundred member patients' organizations, and represent millions of patients from around the world.

- We have created a number of capacity building initiatives such as our twinning programme and regional meetings.

- We influence global decision-making at the World Health Organization as the global voice for patient-centred healthcare. 